\title{
Rare association of prune belly syndrome with pouch colon
}

This article was published in the following Dove Press journal:

Pediatric Health, Medicine and Therapeutics

I4 January 20 I I

Number of times this article has been viewed

\author{
M Ragavan' \\ U Haripriya' \\ PV Pradeep' \\ J Sarvavinothini ${ }^{2}$ \\ 'Department of Endocrine Surgery, \\ ${ }^{2}$ Department of Anaesthesia, Narayana \\ Medical College and Superspeciality \\ Hospital, Nellore, Andhra Pradesh, \\ India
}

\begin{abstract}
Prune belly syndrome is a triad characterized by abdominal wall musculature deficiency, cryptorchidism and urinary tract abnormalities, and is often associated with other anomalies. Although associated anorectal anomalies have been reported with this syndrome, only two cases of pouch colon, a rare type of anorectal malformation, have been reported. We report a case of prune belly syndrome with pouch colon presenting with retention of urine.
\end{abstract}

Keywords: prune belly, triad syndrome, pouch colon, anorectal malformation

\section{Introduction}

Prune belly syndrome is a specific constellation of anomalies, consisting of an abdominal wall deficiency in muscular tissue, a dilated urinary tract, and bilateral cryptorchidism. The syndrome derives its name from its characteristically distended protruding abdominal wall which is thin-walled with wrinkled skin resembling a dried prune. Gastrointestinal anomalies are seen in over $30 \%$ of these patients. Pouch colon is a rare type of anorectal malformation in which the colon is malformed into a retort-shaped pouch partly or totally, and is confined to a few geographical locations, which include the Indian subcontinent. Association of pouch colon with prune belly syndrome is extremely rare, and there are only two such cases reported in the English literature. We report a case of prune belly syndrome with pouch colon presenting with retention of urine.

\section{Case history}

A term male neonate, born by vaginal delivery to a 19 -year-old primigravida, was brought to our hospital at 40 hours of life with an absent anal opening and having not passed urine since birth. The baby looked pink and active, with a $3 \mathrm{~kg}$ birth weight. On examination, a normal cardiovascular and respiratory system was found. The abdomen was flabby, with visible loops of intestine and peristaltic movement. The urinary bladder was distended and decreased in size, with passage of urine when pressure was applied over it. The testes were absent in the scrotum and impalpable on both sides. The penis was conical in shape with a wide base and lax excessive skin, as shown in Figure 1. The urethral meatus was located in the penoscrotal junction and was wide. There was a well formed median raphe on the ventrum of the penis. There was an absent anal opening with a flat perineum, and the gluteal folds were not well formed, as shown in Figure 2. The sacrum was also not well formed. Invertogram showed one large air-fluid level covering more than $50 \%$ of the width 


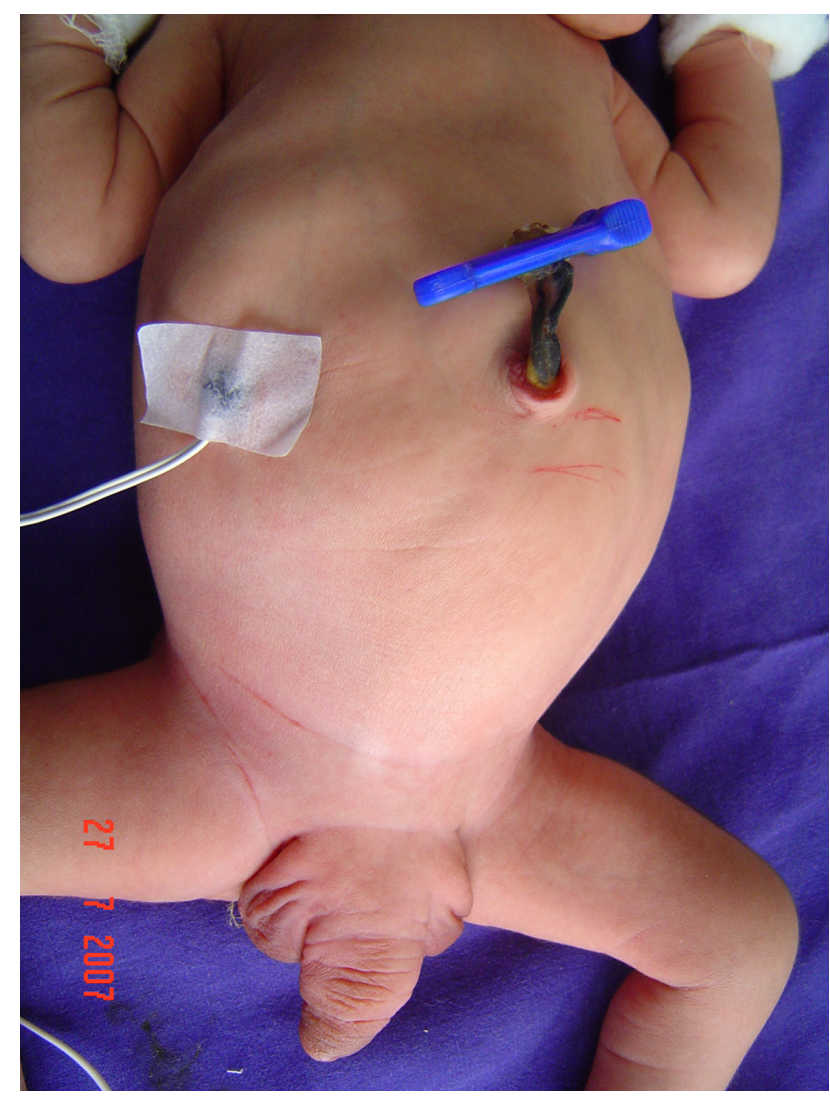

Figure I Flabby abdomen with visible bowels and triangular wide base penis with lax excess skin.

of the abdomen occupying the left iliac fossa and crossing the midline, suggestive of a high anorectal anomaly with pouch colon. Ultrasonogram showed a distended urinary bladder and bilateral grossly hydronephrotic kidneys, with a globular structure in the left iliac fossa. The location of the testes could not be commented on. A micturating cystourethrogram showed a fistulous connection between the bladder and pouch colon, and the posterior urethra was dilated with no outflow obstruction. Under sterile conditions, a bladder catheterization was done with a No. 5 size infant feeding tube. Exploratory laparotomy done by an oblique incision in the left iliac fossa revealed no muscular tissue in the abdominal wall except for the fascial layer. The whole colon was replaced by a pouch-like structure of about $8 \times 8 \mathrm{~cm}$ in size with a colovesical fistula, proximal to the bladder neck and posteriorly. The blood supply to the pouch was mostly from the inferior mesenteric artery, except for the small posterior part being supplied by a twig from the ileocolic artery. It lacked haustrations, appendices epiploicae, and taenia coli. There was an abrupt transition from the normalcaliber proximal bowel to the distal dilated pouch. The blood vessels formed an arcade on the antimesenteric border from

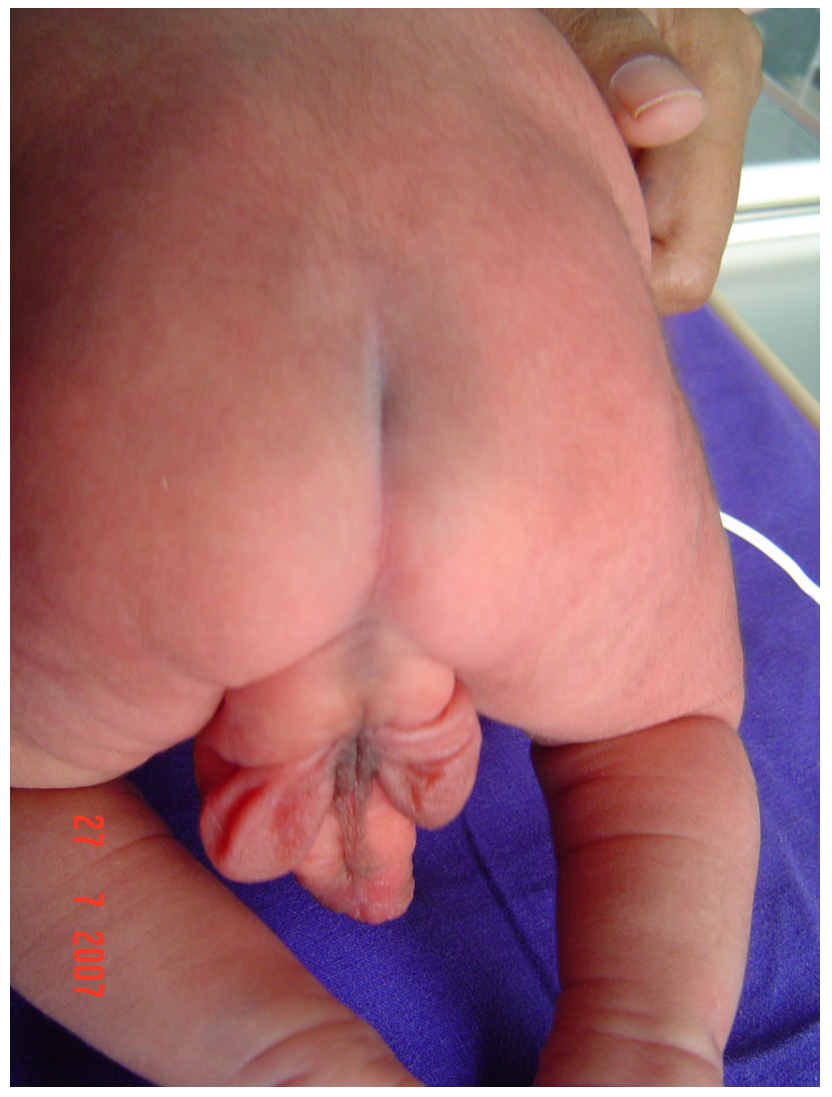

Figure 2 Absent anal opening with flat perineum and empty scrotum with prominent median raphe and hypospadias.

which creeping serpentine-like vessels were going to the bowel wall, as shown in Figure 3. The colovesical fistula was disconnected, and the pouch colon was converted into a tube by "colorrhaphy" from its antimesenteric border for further pullthrough, and was brought out as an endcolostomy. Postoperative recovery was uneventful, and the child was able to void well after catheter removal. In view

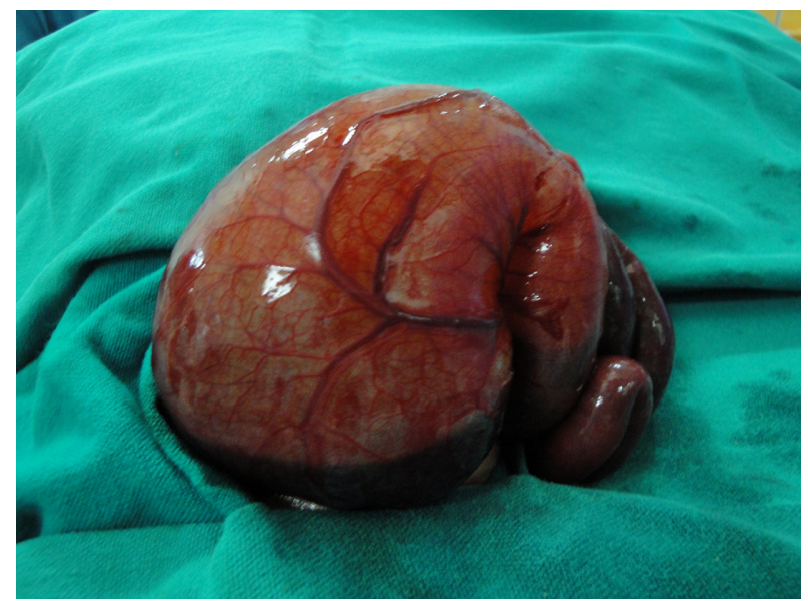

Figure 3 Pouch colon with serpentine vessels on the antimesenteric border. 
of preserved renal function and spontaneous emptying of the bladder, watchful waiting was planned. Histopathological examination of the resected colonic pouch showed normal colonic mucosa and ganglion cells.

\section{Discussion}

Prune belly syndrome represents a spectrum of anomalies first recognized by Frohlich in 1839 and named prune belly syndrome by Osler in $1901 .{ }^{1}$ It is also known as triad syndrome or Eagle-Barrett syndrome, and consists of three major findings, ie, deficiency of the abdominal musculature, bilateral intra-abdominal testes, and an anomalous urinary tract. ${ }^{2}$ Associated gastrointestinal anomalies are seen in over $30 \%$ of patients. Although anorectal agenesis is quite common with prune belly syndrome, congenital pouch colon has been reported in only two cases.

The possible embryogenesis of prune belly syndrome is a fascinating subject for study. However, because no experimental animal model is available, any discussion on the subject has to be largely speculative. Three theories have been put forward to explain this syndrome, ie, early uterourethral obstruction leading to urinary tract dilatation and fetal ascites, the mesodermal arrest theory, and a defect in the yolk sac. ${ }^{3}$ The most tenable theory is a muscular deficiency of the abdominal wall and urinary tract resulting from an early disturbance in embryogenesis due to aberrant mesenchymal development, as opposed to a mechanical obstruction as the cause. ${ }^{4}$ This is further supported by the histological findings in the abdominal wall and urinary and genital tracts, and an association of exomphalos and gastroschisis with prune belly syndrome also strengthens this theory. Ives proposes the timing of the basic defect in disturbance of mesodermal development to be in the third week of gestation, which would account for all three parts of the triad. ${ }^{5}$ The coexistence of anorectal agenesis with pouch colon and genitourinary abnormalities lends credence to the concept of an early error of embryogenesis, but classifying it as a VACTERL anomaly is debatable.

Nearly three-quarters of patients with prune belly syndrome may have cardiac, pulmonary, skeletal, and gastrointestinal anomalies. ${ }^{6}$ Most individuals with this syndrome have intestinal malrotation, persistence of the wide embryonic mesentery, and absence of fixation of the colon to the posterior abdominal wall. ${ }^{7}$ Infants with prune belly syndrome also appear to be at higher risk for persistence of the common fetal cloaca. ${ }^{8}$ The relatively high frequency of distal stenosis and bowel atresia suggests that the anomalous mesenteric attachments may predispose to prenatal volvulus and subsequent anatomic bowel obstruction. This postulate explains why the chance of anorectal malformation is high in patients with prune belly syndrome. Congenital pouch colon, also known as congenital short colon, is an unusual high anorectal malformation in which a varying length of colon is replaced by a dilated pouch that almost invariably has a wide high fistulous communication with the genitourinary tract, and is exclusively found in Southeast Asia, particularly in India. ${ }^{9}$ We assume that the presence of a dilated pouch can aggravate the severity of manifestation of prune belly syndrome, because the pouch in the abdomen and pelvic cavity can behave like a distended bladder urethral obstruction which causes the prune belly syndrome as per the urethral obstruction theory. In our case, there was also postnatal retention of urine in spite of normal urethral outflow. The thick meconium in the bladder coming via the colovesical fistula or the angulations of the bladder neck due to the fistula might have hindered the act of micturition. The possibility of a genetic basis for prune belly syndrome is the subject of debate, in spite of a high incidence of association of prune belly syndrome with trisomies 21,13 , and 18 , because there is $100 \%$ discordance among all twins in whom monozygosity has been proven..$^{5,10}$

\section{Conclusion}

This case is presented because of its rarity, and suggests that further animal studies are needed to determine the precise embryogenesis of prune belly syndrome, especially its association with pouch colon.

\section{Disclosure}

The authors report no conflicts of interest in this work.

\section{References}

1. Woodard JR, Smith EA. Prune belly syndrome. In: Walsh PC, Retik AB, Vaughan ED, Wein AJ, editors. Campbell's Urology. 7th ed. Philadelphia, PA: WB Saunders; 1998.

2. Greskovich FJ 3rd, Nyberg LM Jr. The prune belly syndrome: a review of its etiology, defects, treatment and prognosis. $J$ Urol. 1988;140:707-712.

3. Stephens FD, Gupta D. Pathogenesis of the prune belly syndrome. J Urol. 1994;152:2328-2331.

4. Nunn IN, Stephens FD. The triad syndrome: a composite anomaly of the abdominal wall, urinary system and testis. J Urol. 1961;86:782-794.

5. Ives EJ. The abdominal muscle deficiency triad syndrome: experience with ten cases. Birth Defects. 1974;10:127-135.

6. Geary DF, MacLusky IB, Churchill BM, McLorie G. A broader spectrum of abnormalities in the prune belly syndrome. $J$ Urol. 1986;135:324-326.

7. Silverman FN, Huang N. Congenital absence of the abdominal muscles associated with malformation of the genitourinary and alimentary tracts; report of cases and review of literature. Am J Dis Child. 1950;80:91-124 
8. Wright JR Jr, Barth RF, Neff JC, Poe ET, Sucheston ME, Stempel LE. Gastrointestinal malformations associated with prune belly syndrome: three cases and a review of the literature. Pediatr Pathol. 1986;5: 421-428.

9. Narasimharao KL, Yadav K, Mitra SK, Pathak IC. Congenital short colon with imperforate anus (pouch colon syndrome). Ann Pediatr Surg. 1984;1:159-167.
10. Khoury MJ, Cordero JF, Greenberg F, James LM, Erickson JD. A population study of the VACTERL association: evidence for its etiologic heterogeneity. Pediatrics. 1983;71:815-820.

\section{Publish your work in this journal}

Pediatric Health, Medicine and Therapeutics international, peerreviewed, open access journal publishing original research, reports, editorials, reviews and commentaries. All aspects of health maintenance, preventative measures and disease treatment interventions are addressed within the journal. Practitioners from all disciplines

Submit your manuscript here: http://www.dovepress.com/pediatric-health-medicine-and-therapeutics-journal are invited to submit their work as well as healthcare researchers and patient support groups. The manuscript management system is completely online and includes a very quick and fair peer-review system. Visit $<$ http://www.dovepress.com/testimonials.php $>$ to read real quotes from published authors. 